\title{
Synchrotron diffraction characterization of alternative powder diffraction standards
}

\author{
Martinez, L. G. ${ }^{1}$; Ichikawa, R. U. ${ }^{1}$; Imakuma, K. ${ }^{1}$; Orlando, M. T. D. ${ }^{2}$; Turrillas, X. ${ }^{3}$ \\ 1 Nuclear and Energy Research Institute, IPEN/CNEN, São Paulo, SP, Brazil \\ 2 Federal University of Espírito Santo, Vitória, ES, Brazil \\ 3 Materials Science Institute of Barcelona - ICMAB (CSIC), UAB Campus, Catalonia, Spain
}

\begin{abstract}
A set of standard reference materials (SRM) for powder diffraction were developed at the Laboratory of Applied Crystallography of the Nuclear and Energy Research Institute - IPEN/CNEN, aiming to offer an alternative to the expensive standards produced and sold by the US National Institute of Standards and Technology - NIST. The materials studied as standards were high purity samples of $\mathrm{CeO}_{2}, \mathrm{Y}_{2} \mathrm{O}_{3}$, $\mathrm{Si}$ and $\mathrm{Al}_{2} \mathrm{O}_{3}$ submitted to thermal treatments and careful selection by sieving. These standard materials were characterized by diffraction at two synchrotron sources and were compared to the NIST ones. The results show that the produced SRM's present quality similar or, in some cases, superior to the NIST ones.
\end{abstract}

Keywords: standard reference materials, powder diffraction, synchrotron

\section{Introduction}

X-ray powder diffraction is one of the most useful tools in the study and development of materials. To achieve precision and repeatability the calibration of the XRD instruments is extremely important. The calibration of diffraction equipment require the use of standard samples for the alignment of the geometry, determination of radiation wavelengths and intrinsic instrumental resolution for conventional, synchrotron and neutron powder diffractometers. Furthermore, for some experimental procedures it may be necessary the use of internal standards mixed to samples to calibrate the position of reflections or their intensities [1]. Additionally, for size-strain profile analysis a standard material is generally necessary to determine and correct the instrumental broadening. The requirements for these materials, known as standard reference materials (SRM), may vary for each application but, in general, must: be stable with well-defined cell parameters, present intense reflections without overlaps, present large crystallite sizes and negligible microstrains [2]. The SRM's widely used for these applications are the Standard Reference Materials for Powder Diffraction produced and sold by the US National Institute of Standards and Technology - NIST. However, due to their high prices, some laboratories do not use these standards or produce their own "homemade" standards, usually not certified [2]. In order to provide an alternative to NIST standards we developed a set of SRM samples especially treated in order to present the required properties for a SRM [2].

In this work are presented the results for these samples which are compared to the results of NIST SRM's.

\section{Materials and methods}

The starting materials were high purity $\mathrm{CeO}_{2}, \mathrm{Si}, \mathrm{Y}_{2} \mathrm{O}_{3}$ and $\mathrm{Al}_{2} \mathrm{O}_{3}$ which were heat treated and selected by sieving in order to present high crystallite sizes, negligible microstrains, and particle sizes in the range of 37 to $44 \mu \mathrm{m}$, as described in previous works [2-5]. These SRM samples, named "IPEN-SRM" were analyzed by high-resolution synchrotron diffraction at the Brazilian Synchrotron Laboratory (LNLS - Campinas - Brazil) and at Alba Synchrotron (Barcelona - Spain) and compared to the NIST SRM samples.

In Tab. 1 are shown the conditions of heat treatment for each material.

Table 1: Conditions used for the heat treatments of the materials.

\begin{tabular}{|l|c|c|c|c|}
\hline Material & $\mathbf{C e O}_{\mathbf{2}}$ & $\mathbf{S i}$ & $\mathbf{Y}_{\mathbf{2}} \mathbf{O}_{\mathbf{3}}$ & $\mathbf{A l}_{\mathbf{2}} \mathbf{O}_{\mathbf{3}}$ \\
\hline Temperature $\left({ }^{\circ} \mathbf{C}\right)$ & 1350 & 900 & 1350 & 1300 \\
\hline Time (h) & 72 & 24 & 72 & 72 \\
\hline Ambient & Air & Vacuum & Air & Air \\
\hline
\end{tabular}

\section{Results}

In Fig. 1 are shown the diffraction profiles for (a) $\mathrm{CeO}_{2}$, (b) $\mathrm{Y}_{2} \mathrm{O}_{3}$, (c) $\mathrm{Al}_{2} \mathrm{O}_{3}$ and (d) $\mathrm{Si}$, measured at the Brazilian National Synchrotron Laboratory - LNLS (Campinas Brazil) in high-resolution configuration.

In Fig. 2 are shown the diffraction profiles for (a) $\mathrm{Y}_{2} \mathrm{O}_{3}$, (b) $\mathrm{Si}$ and (c) $\mathrm{CeO}_{2}$, measured at the ALBA Synchrotron Facility (Barcelona - Spain). 

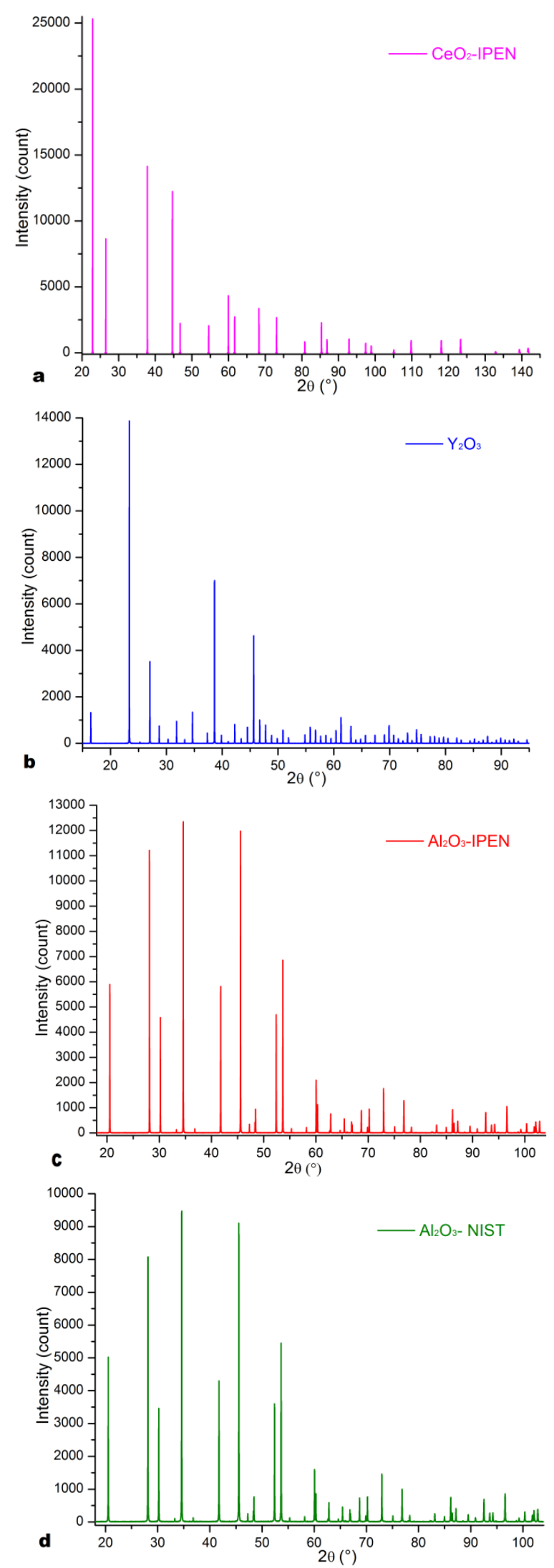

Figure 1: High-resolution synchrotron diffraction profiles measured at LNLS (Campinas - Brazil) for (a) $\mathrm{CeO}_{2}$, (b) $\mathrm{Y}_{2} \mathrm{O}_{3}$, (c) $\mathrm{Al}_{2} \mathrm{O}_{3}$ SRM's produced at IPEN and (d) NIST- $\mathrm{Al}_{2} \mathrm{O}_{3}$.

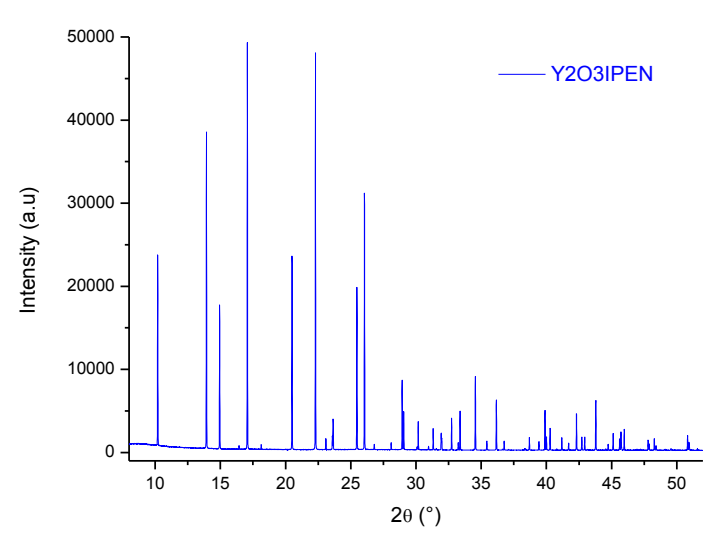

a

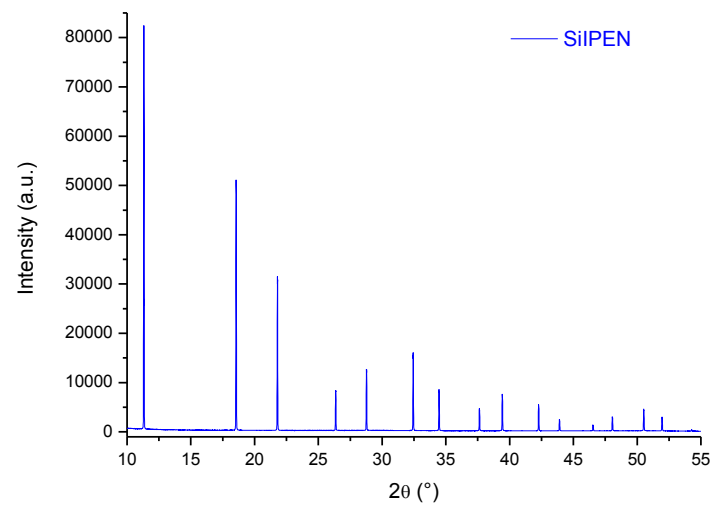

b

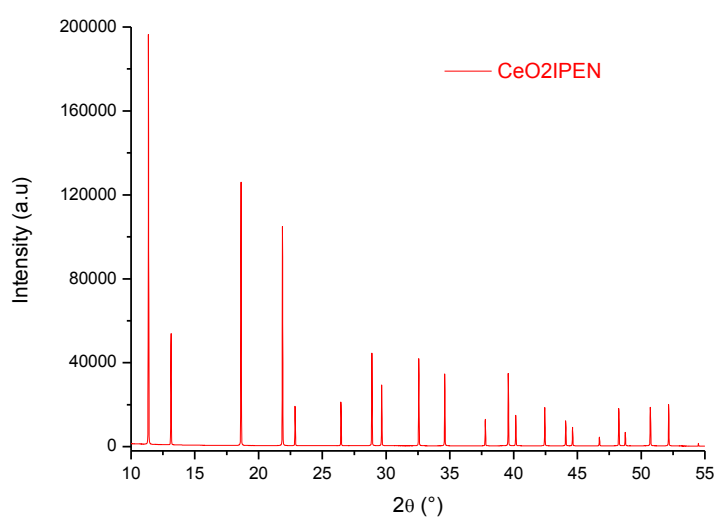

C

Figure 2: High-resolution and high-energy synchrotron diffraction profiles measured at ALBA Synchrotron Source (Barcelona - Spain) for (a) $\mathrm{Y}_{2} \mathrm{O}_{3}$, (b) $\mathrm{Si}$ and (c) $\mathrm{CeO}_{2}$ SRM's produced at IPEN.

From Figs. 1 and 2 it can be seen that all the SRM's present narrow and high intensity diffraction profiles, as expected for ideal diffraction standards.

In Fig. 3 are shown details of normalized XRD profiles for IPEN's and NIST's $\mathrm{Al}_{2} \mathrm{O}_{3}$ samples in which it can be seen that the IPEN's sample profile presents more symmetrical and narrow reflections. 


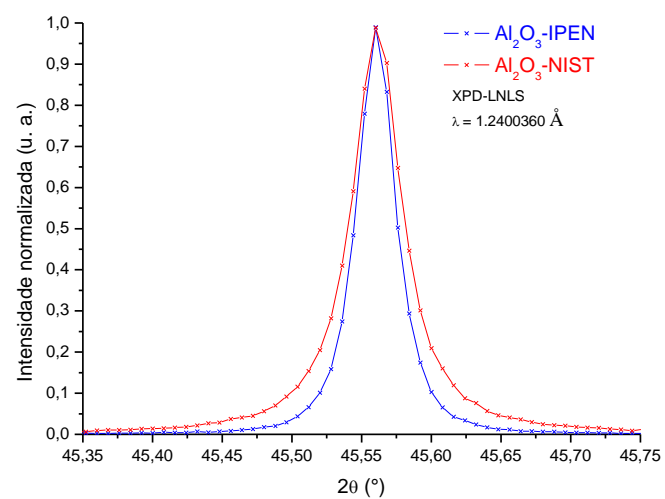

a

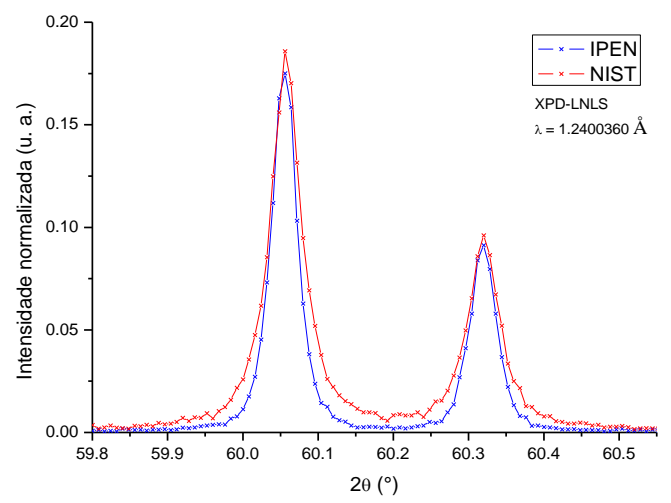

b

Figure 3: Details of normalized XRD profiles for IPEN and NIST $\mathrm{Al}_{2} \mathrm{O}_{3}$ samples.

In Tab 2 are presented results for cell parameters and mean crystallite sizes for the IPEN's and NIST's SRM materials. In the table the superscripts "a" indicate the values determined by the fitting of the cell parameter calculated for each peak (ankl) multiplied by $\cos \theta$, extrapolated to $\cos ^{2} \theta=0$; superscripts " $b$ " indicate the values obtained by Rietveld refinement and superscripts "c" indicate the NIST certified values. The mean crystallite sizes were calculated by Scherrer method.

Table 2: Cell parameters and crystallites sizes for IPEN's and NIST's standard materials measured with high resolution synchrotron radiation $(\lambda=0.12400360 \mathrm{~nm})$.

\begin{tabular}{|l|l|c|}
\hline \multicolumn{1}{|c|}{ SRM } & \multicolumn{1}{|c|}{$\begin{array}{c}\text { Cell parameter } \\
(\mathbf{n m})\end{array}$} & $\begin{array}{c}\text { Mean crystallite } \\
\text { size }^{\mathrm{d}}(\mathbf{n m})\end{array}$ \\
\hline $\mathrm{CeO}_{2}$-IPEN & $\mathrm{a}=0.541147^{\mathrm{a}}$ & 615 \\
\hline Si-IPEN & $\mathrm{a}=0.543104^{\mathrm{a}}$ & 520 \\
\hline Si-NIST & $\begin{array}{l}\mathrm{a}=0.543091^{\mathrm{a}} \\
\mathrm{a}=0.543123^{\mathrm{c}}\end{array}$ & 465 \\
\hline $\mathbf{Y}_{\mathbf{2}} \mathrm{O}_{3}$-IPEN & $\begin{array}{l}\mathrm{a}=1.06055^{\mathrm{a}} \\
\mathrm{a}=1.0604193(6)^{\mathrm{b}}\end{array}$ & 345 \\
\hline $\mathrm{Al}_{2} \mathrm{O}_{3}$-IPEN & $\begin{array}{l}\mathrm{a}=0.4758846(8)^{\mathrm{b}} \\
\mathrm{c}=1.2991817(34)^{\mathrm{b}}\end{array}$ & 278 \\
\hline $\mathrm{Al}_{2} \mathrm{O}_{3}$-NIST & $\begin{array}{l}\mathrm{a}=0.4759091^{\mathrm{c}} \\
\mathrm{c}=1.2991779^{\mathrm{c}}\end{array}$ & 192 \\
\hline
\end{tabular}

a: From fitting $a_{0} x \cos ^{2} \theta$ extrapolated to $\cos ^{2} \theta=0$; $b$ : from Rietveld refinement; $c$ : NIST certified values; $d$ : from Scherrer method.
From Tab. 2 it can be observed that in the cases in which there are similar IPEN and NIST SRM's $\left(\mathrm{Al}_{2} \mathrm{O}_{3}\right.$ and $\mathrm{Si}$ ) the IPEN's ones present higher crystallite sizes, which is evidenced by the narrower reflections of $\mathrm{Al}_{2} \mathrm{O}_{3}-$ IPEN sample compared to $\mathrm{Al}_{2} \mathrm{O}_{3}-\mathrm{NIST}$ sample as can be seen in Fig. 3.

The $\mathrm{CeO}_{2}$-IPEN SRM presents the highest mean crystallite size, denoting that it is a good standard for instrumental breadth determination. The $\mathrm{Y}_{2} \mathrm{O}_{3}$-IPEN SRM also presents high crystallite size and, additionally, a great number of reflections, which make it a good standard for Rietveld refinement method for which this characteristic allows good determinations of profile function and instrumental parameters.

The $\mathrm{Al}_{2} \mathrm{O}_{3}$-IPEN SRM presents more symmetric and narrow profiles than NIST's sample, evidencing its higher crystallinity.

\section{Conclusion}

It can be concluded that the IPEN's powder diffraction SRM's are fully similar or, for some of them, better than NIST SRM's.

The IPEN powder diffraction SRM's are already being used in more than 25 research laboratories in Brazil and abroad, including LNLS and ALBA synchrotrons Laboratories and IPEN's neutron powder diffractometer.

\section{Acknowledgements}

The authors acknowledge the support from Brazilian National Research Council - CNPq (contract \#480337/2007-1) and to Brazilian National Synchrotron Light Laboratory - LNLS and ALBA Synchrotron Light Source. R. U. Ichikawa acknowledges CNEN for the scholarship granted.

\section{References}

[1] LANGFORD, J. I.; LOUER, D. Powder Diffraction. Rep. Prog. Phys. v. 59, p.131-234, 1996.

[2] GALVÃO, A. S. A. Desenvolvimento de amostras padrão de referência para difratometria. 95 p. MSc. Dissertation (Nuclear Technology), Programa de PósGraduação em Tecnologia Nuclear, Instituto de Pesquisas Energéticas e Nucleares, Universidade de São Paulo, São Paulo, 2011 (in portuguese).

[3] MARTINEZ, L. G.; ORLANDO, M. T. D.; CORRÊA, H P S; FERREIRA, F. F.; PAIVA-SANTOS, C. O. Production of standard reference samples for powder diffraction. 18 Congresso Brasileiro de Engenharia e Ciência dos Materiais, 2008, Porto de Galinhas, PE. 2008.

[4] TURRILLAS, X.; MARTINEZ, L.G.; IMAKUMA, K.; ICHIKAWA, R. U. Characterization of Alternative Standard Reference Materials for Conventional and Synchrotron X-Ray Powder Diffraction. ALBA User Meeting 2013, Cerdanyola del Vallès, Spain. Proceedings of the ALBA User Meeting 2013. v. 1. 